\title{
Action of db-cAMP on the bystander effect and chemosensitivity through connexin 43 and Bcl-2-mediated pathways in medulloblastoma cells
}

\author{
PEIXIN SUN ${ }^{1,2^{*}}$, YUNHUI LIU ${ }^{1 *}$, HAOQIANG YING ${ }^{1}$ and SHAOYI LI ${ }^{1}$ \\ ${ }^{1}$ Department of Neurosurgery, Shengjing Hospital of China Medical University, Shenyang 110004; \\ ${ }^{2}$ Department of Neurosurgery, Liaoning Province Tumor Hospital, Shenyang 110042, P.R. China
}

Received March 20,2012; Accepted May 30, 2012

DOI: $10.3892 /$ or.2012.1900

\begin{abstract}
Medulloblastoma (MB) is one of the most common malignant brain tumors of childhood and is associated with a poor prognosis. Gap-junctional intercellular communication (GJIC) is an important mode for cell-to-cell communication. Dysfunctional GJIC is exhibited in most cancer cells. There is significant evidence that GJIC is important in at least some prodrug/suicide gene systems by augmenting the bystander effect (BE). GJIC is made up of connexins (Cxs), among which $\mathrm{Cx} 43$ is present in most tissues. Bcl-2, an important apoptosis blocker, is closely associated with the sensitivity to anticancer drugs. Our study showed that dibutyryl cyclic adenosine monophosphate (db-cAMP) upregulated the $\mathrm{Cx} 43$ expression and GJIC function in Daoy medulloblastoma cells. It directly enhanced the BE using a herpes simplex virus thymidine kinase (HSV-tk)/ganciclovir (GCV) system, which was blocked by a $\mathrm{Cx} 43$ inhibitor. In addition, db-cAMP increased the cytotoxicity of temozolomide and teniposide, possibly by downregulating the Bcl-2 expression and inducing apoptosis. Taken together, we demonstrated the beneficial effect of db-cAMP in treating medulloblastoma depending on the upregulation of $\mathrm{BE}$ and chemosensitivity through $\mathrm{Cx} 43$ and Bcl-2-mediated pathways.
\end{abstract}

\section{Introduction}

Medulloblastoma (MB) is the most common malignant brain tumors of childhood, accounting for $>20 \%$ of pediatric brain

Correspondence to: Dr Yunhui Liu, Department of Neurosurgery, Shengjing Hospital of China Medical University, No. 36 Sanhao Street, Heping, Shenyang 110004, P.R. China

E-mail: liuyunhui_cmu@163.com

*Contributed equally

Key words: db-cAMP, connexin 43, Bcl-2, bystander effect, chemosensitivity, medulloblastoma tumors. Despite recent advances in the treatment of medulloblastoma including improved surgical resection techniques, radiation and chemotherapy $(1,2)$, the prognosis is still relatively poor in infants. Gene therapy, particularly suicide gene therapy may offer an attractive approach for the treatment of these patients. However, gene therapy trials have often produced poor results. Present delivery systems, such as adenoviruses or retroviruses, are unable to reach the total cancer population $(3,4)$. Therefore, the enhancement of the so-called 'bystander effect' (BE) in which tumor cells that are not transduced with the suicide gene are also eliminated along with gene-transduced cells may have a significant impact on the therapeutic efficacy.

Gap-junctional intercellular communication (GJIC) is an important factor in the cell-to-cell communication in cellular homeostasis, normal embryonic development $(5,6)$, differentiation, and the regulation of cellular proliferation (7). Dysfunctional GJIC is exhibited in most cancer cells (8). There is evidence that GJIC is important in at least some prodrug/ suicide gene systems $(9,10)$ by augmenting BE. GJIC is made up of hemichannels (called connexons) in the membrane of one cell joined in mirror symmetry with the same number of hemichannels in the opposing cell membrane, which are composed of six subunits called connexins (Cxs) (11). Among various $\mathrm{Cxs}, \mathrm{Cx} 43$ is present in most tissues or cell types and is reduced in cancer and chemically transformed cells (12-14). Rosolen et al (15) reported a suboptimal in vivo effect of the suicide gene therapy in treating $\mathrm{MB}$, which might partially be explained by a limited BE coupled with a low expression of $\mathrm{Cx} 43$ protein. More importantly, the transfection of Cx43 was found to increase sensitivity to several chemotherapeutic agents in human glioblastoma U251 cells (16). Our previous study showed that $\mathrm{Cx} 43$ expression is increased when Daoy cells are co-cultured with neural stem C17.2 cells, which may be one way of augmentating BE (17). A large body of experimental evidence suggests that apoptosis is regulated by both apoptosis blockers and apoptosis promoters. Bcl-2, an important apoptosis blocker, is known to be closely associated with the sensitivity to anticancer drugs. Elevated levels of Bcl-2 protein in gene-transfection experiments lead to the increased resistance to a wide variety of chemotherapeutic drugs as well as radiation (18-20). Therefore, identification of 
an effective agent which may influence both $\mathrm{Cx} 43$ and Bcl-2 in the treatment of MB is needed.

In the present study, we investigated the effect of dibutyryl cyclic adenosine monophosphate (db-cAMP) on BE and chemosensitivity in human medulloblastoma Daoy cells. Our results showed that db-cAMP upregulates $\mathrm{Cx} 43$ protein expression and thus the GJIC function, which may possibly result in the enhancement of $\mathrm{BE}$ in the herpes simplex virus thymidine kinase (HSV-tk)/ganciclovir (GCV) system. Meanwhile, db-cAMP increased the cytotoxicity of temozolomide and teniposide in Daoy cells, possibly by downregulating the $\mathrm{Bcl}-2$ expression and increasing apoptosis.

\section{Materials and methods}

Cell culture. D283Med, Daoy and D341Med cells (originally obtained from the American Type Culture Collection, ATCC) were maintained in an Advanced-Minimal Essential medium (Sigma-Aldrich, St. Louis, MO, USA) at $37^{\circ} \mathrm{C}$ under $5 \%$ $\mathrm{CO}_{2}$, supplemented with $10 \%$ fetal bovine serum, $2 \mathrm{mmol} / \mathrm{l}$ L-glutamine, $2 \mathrm{mmol} / 1$ sodium pyruvate, $100 \mathrm{U} / \mathrm{ml}$ penicillin, and $100 \mu \mathrm{g} / \mathrm{ml}$ streptomycin. As was indicated, db-cAMP (Sigma-Aldrich) was added at a final concentration of $0.5 \mathrm{mmol} / \mathrm{l}$ and gossypol at a final concentration of $5 \mu \mathrm{mol} / \mathrm{l}$, both of which, based on the result of preliminary study, have no toxic effect on Daoy cells.

Western blot analysis. Cell lysis from different cell lines or brain tissues were extracted as usual, separated by SDS-polyacrylamide gel and transferred to polyvinylidene difluoride membranes (Millipore, Bedford, MA, USA). The membranes were then incubated with an anti-Cx43 or Bcl-2 monoclonal antibody (Sigma-Aldrich) diluted to 1:200, followed by incubation with a rabbit anti-mouse horseradish peroxidase conjugated IgG. The ECL western blot analysis kit (Amersham, Italy) was used to observe the results.

Scrape-loading and dye transfer. To assess GJIC function under different conditions, the scrape-loading and dye transfer (SL/DT) assay was carried out. Daoy cells were treated with db-cAMP for 12, 24 or $72 \mathrm{~h}$, followed by incubation with gossypol for another 12 or $48 \mathrm{~h}$. Daoy cells grown on glass chambers were rinsed with PBS. A scrape through the monolayer was made with a needle in the presence of $0.5 \%$ hydrophilic dye Lucifer yellow in the extracellular solution. After incubation for $3 \mathrm{~min}$ at room temperature, cells were washed with PBS and then incubated for another $5 \mathrm{~min}$. Cells were then fixed with $4 \%$ paraformaldehyde and observed under a confocal microscope (Olympus, Tokyo, Japan) to measure the longest distance of Lucifer yellow from the scrape.

Retroviral vectors and stable transfection. The HSV-tk retrovirus-producing cells (PA317, mouse fibroblast cell line with $H S V$ - $t k$ gene) were obtained from Genetic Therapy, Inc., (Gaithersburg, MD, USA). To produce a virus-containing supernatant, the cells were plated in $75-\mathrm{cm}^{2}$ flasks in DMEM with high glucose and $10 \%$ heat-inactivated foetal calf serum. After 24-48 h of incubation, the supernatant was collected, filtered and stored at $-80^{\circ} \mathrm{C}$ until use. Parental Daoy cells were incubated in a $75-\mathrm{cm}^{2}$ flask and then transferred to 6-well plates. Twenty-four hours later, $2 \times 10^{5}$ cells were incubated in a supernatant containing vectors with $4 \mu \mathrm{g} / \mathrm{ml}$ Polybrene (Sigma-Aldrich) for $24 \mathrm{~h}$ before being cultured in normal medium. The cells were then exposed to $1 \mathrm{mg} / \mathrm{ml} \mathrm{G}-418$ (Life Technologies, Carlsbad, CA, USA) for drug selections. After 2 weeks of G-418 selection, resistant cells were obtained for consecutive experiments.

Indirect immunofluorescence assay. Diluted serum $(20 \mu \mathrm{l})$ (1:10) was added onto slides containing a monolayer of transfected cells, which were fixed in acetone for $10 \mathrm{~min}$. The slides were incubated in $0.2 \%$ Triton X-100 at room temperature for $10 \mathrm{~min}$, washed three times with phosphate-buffered saline (PBS) and then maintained in non-immune serum and incubated at $37^{\circ} \mathrm{C}$ for another $30 \mathrm{~min}$. After the serum was removed, the antibody against HSV-tk (diluted 1:100) or Myc (diluted 1:50) (Santa Cruz Biotechnology, Santa Cruz, CA, USA) was added and incubated at $4^{\circ} \mathrm{C}$ overnight. After being washed three times with PBS, the slides were incubated with fluorescein isothiocyanate (FITC)-labeled rabbit anti-mouse IgG for $30 \mathrm{~min}$. Nuclei were stained with $2 \mu \mathrm{g} / \mathrm{ml}$ Hoechst 33342 at $37^{\circ} \mathrm{C}$ for $20 \mathrm{~min}$ and then fluorescence was detected.

$R T$-PCR. Total RNA was isolated from Daoy cells using TRIzol reagent (Invitrogen, Carlsbad, CA, USA), and cDNA was synthesized with the cDNA Synthesis kit (Roche, Basel, Switzerland). The primers for HSV-tk and $\beta$-actin were: HSV-tk 5'-GCGC GTATGGCTTCGTACCC-3' (sense) and 5'-TCCTTGCGTGT TTCAGTTAGCCTC-3' (antisense); $\beta$-actin, 5'-TCACCCAC ACTGTGCCCATCTACGA-3' (sense) and 5'-CAGCGGAACC GCTCATTGCCAATGG-3' (antisense). PCRs were carried out under optimized conditions. Agarose electrophoresis (2\%) was used for detection. The integrated density values (IDV) were calculated with $\beta$-actin as an internal control.

MTT assay. An MTT assay was performed to detect the effect of db-cAMP on BE, GCV cytotoxicity, and the toxicity of various drugs in Daoy cells. Briefly, $20 \mu \mathrm{l}$ of MTT was added to treated or untreated Daoy cells at a final concentration of $5 \mathrm{mg} / \mathrm{ml}$, and cells were incubated for another $4 \mathrm{~h}$ at $37^{\circ} \mathrm{C}$ and dissolved by $150 \mu 1$ DMSO (Sigma-Aldrich). Finally, plates were read on a microplate reader at $570 \mathrm{~nm}$. For BE, cells were treated with $0.5 \mathrm{mmol} / 1 \mathrm{db}-\mathrm{cAMP}$ for $72 \mathrm{~h}$ or with $0.5 \mathrm{mmol} / \mathrm{l} \mathrm{db}$-cAMP for $24 \mathrm{~h}$, followed by gossypol for another $48 \mathrm{~h}$, and mixing experiments were carried out and the ratio of $\mathrm{tk}^{+} / \mathrm{tk}$ cells for $50 \%$ cell killing was detected. For GCV toxicity, cells were treated with $100 \mu \mathrm{mol} / 1 \mathrm{GCV}$ combined with or without $0.5 \mathrm{mmol} / \mathrm{ldb}$-cAMP for 24 or $72 \mathrm{~h}$, and the ratio of the OD value of db-cAMP-treated cells to that of untreated cells was calculated to assess cell survival. For drug toxicity assay, cells were treated with temozolomide or teniposide combined with or without $0.5 \mathrm{mmol} / \mathrm{l} \mathrm{db}$-cAMP or a Bcl-2 family antagonist (ABT-737, $0.01 \mu \mathrm{mol} / \mathrm{l})$ and the inhibition concentration of $50 \%$ cell growth $\left(\mathrm{IC}_{50}\right)$ was calculated for various drugs.

Flow cytometry. To detect apoptosis, Daoy cells treated with db-cAMP (combined with or without gossypol) were collected and incubated with propidium iodide (PI) (SigmaAldrich) solution for $45 \mathrm{~min}$ at $4^{\circ} \mathrm{C}$ in the dark. Then the cells 


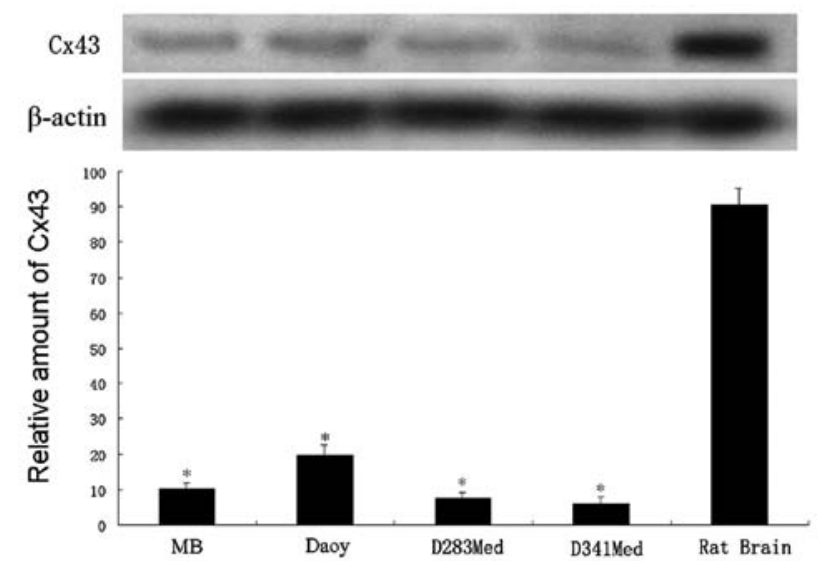

Figure 1. Expression of $\mathrm{Cx} 43$ in primary human medulloblastoma (MD) and in different MD cell lines with normal rat brain tissues as the control. The results of western blot analysis showed low expression levels of Cx43 in the case of primary human MB tissues and in all 3 medulloblastoma cell lines (D283Med, Daoy and D341Med, respectively). The results represent the mean \pm SD of triplicates $\left({ }^{*} \mathrm{P}<0.05\right.$, compared with the control group).

were analyzed by flow cytometric analysis using ModFit LT 3.0 software.

Statistical analysis. Data were compared by Mann-Whitney U and Kruskal-Wallis non-parametric tests. $\mathrm{P}<0.05$ was considered significant. The statistical process was completed using SPSS 13.0 software.

\section{Results}

Influence of db-cAMP on CX43 expression and GJIC function in medulloblastoma cells. To elucidate the role of $\mathrm{Cx} 43$ in medulloblastoma, we first examined its expression in a case of primary human MB and different medulloblastoma cell lines with normal rat brain tissues as the control. As expected, the results of western blot analysis (Fig. 1) showed low expression levels of Cx43 in MB tissues and in all 3 cell lines (D283Med, Daoy and D341Med, respectively), indicating the effect of Cx43 on the development or progression of medulloblastoma. Daoy cells were used in the following study.

We then detected the changes of $\mathrm{Cx} 43$ protein levels following the treatment of Daoy cells with db-cAMP by western blotting. As noted in Fig. 2, in the basal state, Daoy cells expressed a comparatively low level of $\mathrm{Cx} 43$ protein. A non-toxic dose of db-cAMP $(0.5 \mathrm{mmol} / \mathrm{l})$ led to an increase in the $\mathrm{Cx} 43$ protein $(43 \mathrm{kDa})$ as well as its phosphorylated forms (44 and $46 \mathrm{kDa}$ ), reaching 2 -fold over the control. When cells were treated with 1 or $1.5 \mathrm{mmol} / \mathrm{l} \mathrm{db}$-cAMP, the $\mathrm{Cx} 43$ protein, as well as its phosphorylation forms, was further increased to $\sim 3$-fold of the control. Notably, despite the increasing concentration of db-cAMP from 1.0 to $1.5 \mathrm{mmol} / 1$ the $\mathrm{Cx} 43$ protein was not increased, but slightly reduced. Meanwhile, the $\mathrm{Cx} 43$ protein and its phosphorylated forms declined to $\sim$ one-fourth of the control, with the treatment of db-cAMP $(0.5 \mathrm{mmol} / \mathrm{l})$ together with gossypol, a Cx43 inhibitor. These results suggest that db-cAMP significantly increases the expression of the $\mathrm{Cx} 43$ protein and its phophorylated forms in Daoy cells in a concentration-dependent manner.
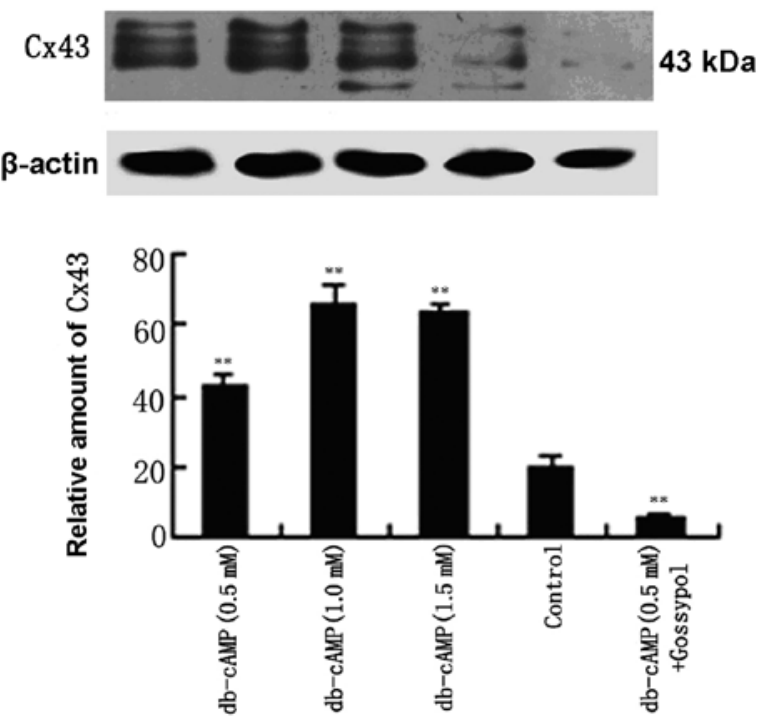

Figure 2. Effect of db-cAMP on $\mathrm{Cx} 43$ protein expression. Protein extracts from Daoy cells treated with $0.5,1.0$ and $1.5 \mathrm{mmol} / \mathrm{l} \mathrm{db}-\mathrm{cAMP}$ (lane 1,2 and 3, respectively), or treated with $0.5 \mathrm{mmol} / 1 \mathrm{db}$-cAMP combined with gossypol (lane 5) were analyzed using western blotting. Cx43 protein and its phophorylation forms visualized by immunoreactive bands at $43 \mathrm{kDa}$ (unphosphorylated form), 44 and $46 \mathrm{kDa}$ (phophorylated form). The results showed that db-cAMP upregulated $\mathrm{Cx} 43$ expression in a concentrationdependent manner. The data represent the means of 3 separate experiments. $\left({ }^{* *} \mathrm{P}<0.01\right.$, compared with the control group).

Subsequently, we evaluated the GJIC function of Daoy cells by conducting a scrape-loading and dye transfer (SL/DT) assay. Functional GJIC was determined in the intercellular transfer of Lucifer yellow after using the scrape-loading assay. The diffusion length of the Lucifer yellow was $501.04 \pm 17.76 \mu \mathrm{m}$, measured at $5 \mathrm{~min}$, in cells treated with db-cAMP for $72 \mathrm{~h}$, which was significantly faster $(\mathrm{P}<0.01)$ than $290.22 \pm 12.27 \mu \mathrm{m}$ in cells treated for $24 \mathrm{~h}$ (Fig. 3). Compared with the control, the GJIC function in cells treated with db-cAMP was greatly enhanced at both 24 and $72 \mathrm{~h}(\mathrm{P}<0.01)$, which was blocked by gossypol, suggesting the involvement of $\mathrm{Cx} 43$ in the effect of $\mathrm{db}$-cAMP on GJIC function.

Identification of HSV-tk-transfected cells. To assess the BE, we transfected Daoy cells with retroviral vectors containing the $H S V$ - $t k$ gene. The transfection efficiency was first detected using indirect immunofluorescence asssy. As shown in Fig. 4, the retroviral vectors were successfully transfected and $H S V$ - $t k$ was expressed in Daoy cells.

Furthermore, we detected the mRNA expression of the $H S V$ - $t k$ gene in transfected Daoy cells. RT-PCR results showed a $H S V$-tk band (Fig. 5), suggesting the stable expression of the gene in the cells.

Effect of $d b$-cAMP on BE in the HSV-tk/GCV system. To evaluate the influence of db-cAMP on BE, MTT was performed. As shown in Fig. 6, db-cAMP markedly enhanced the BE compared with control cells when the ratio of $\mathrm{tk}^{+} / \mathrm{tk}^{\mathrm{k}}$ cells was 1:1-1:16 $(\mathrm{P}<0.05)$. GCV treatment without db-cAMP obtained $50 \%$ cell killing at the ratio of $1: 2 \mathrm{of} \mathrm{tk}^{+} / \mathrm{tk}^{-}$cells, but only the ratio of 1:8 was needed in the presence of db-cAMP $(\mathrm{P}<0.05)$. Significant $\mathrm{BE}$ could be observed when the ratio of $\mathrm{tk}^{+} / \mathrm{tk}$ cells 
A

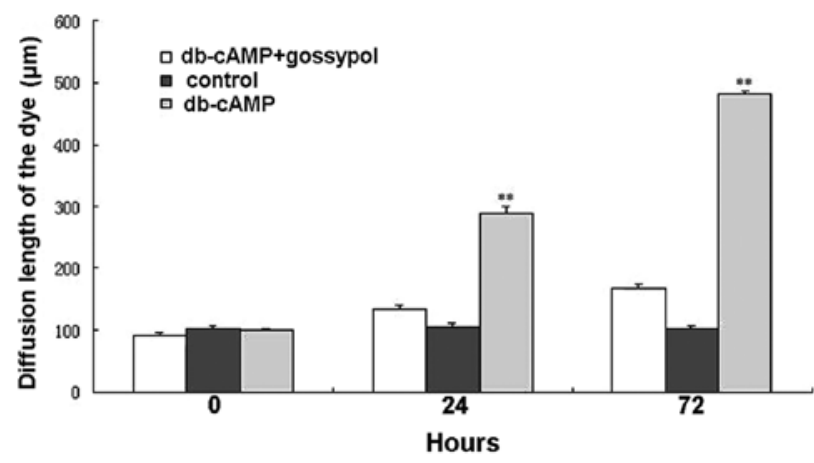

B

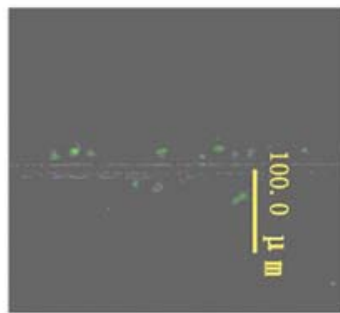

$5 \mathrm{~min}$

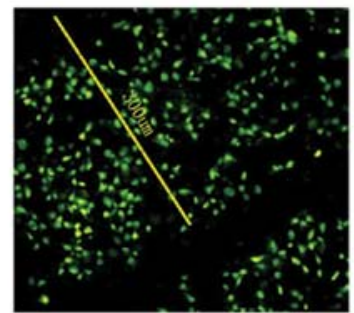

$24 \mathrm{~h}$

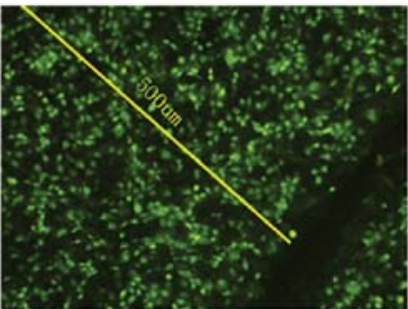

$72 \mathrm{~h}$

Figure 3. Effect of db-cAMP on GJIC function. GJIC function in Daoy cells under different conditions was measured by SL/DT assay. (A) The software was used to measure the average diffusion distance in Daoy cells treated by db-cAMP for 0, 24 and $72 \mathrm{~h}$, respectively, with or without gossypol. The results of the statistical analysis showed no significant difference in the average diffusion distance at $0 \mathrm{~h}$ under all culture conditions $(\mathrm{P}>0.05)$. The average diffusion distance was significantly higher at 24 and $72 \mathrm{~h}$ in db-cAMP-treated cells than that of the control $\left.{ }^{* * *} \mathrm{P}<0.01\right)$ and was blocked by gossypol. The results represent the means of 3 separate experiments \pm SD. (B) Diffusion of the Lucifer yellow in the Daoy cells following the treatment with db-cAMP at different time points.

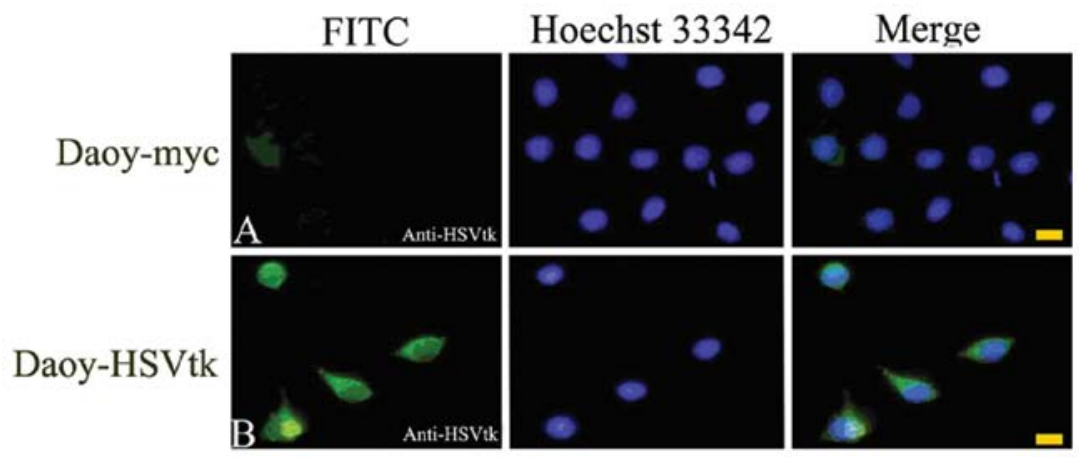

Figure 4. Identification of transfection efficiency by indirect immunofluorescence assay. (A) Control group; (B) Daoy cells transfected with retroviral vectors containing the $H S V$ - $t k$ gene.

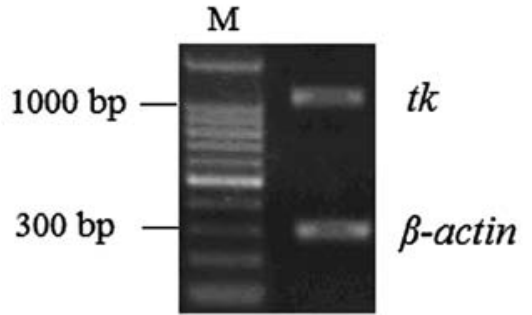

Figure 5. Result of RT-PCR after transfection with $\beta$-actin as an internal control. M, 100-bp DNA ladder.

was as low as 1:16 in the presence of db-cAMP, but at the ratio of 1:4 in the absence of db-cAMP. The cytotoxicity was the same in the presence or absence of db-cAMP when the ratio of $\mathrm{tk}^{+} / \mathrm{tk}$ cells was 2:1 ( $\left.>0.05\right)$. Compared with untreated cells, a decrease was observed in cell killing when Daoy cells were treated with db-cAMP combined with gossypol, indicating a role of $\mathrm{Cx} 43$ in the effect of db-cAMP on BE.

Moreover, we also investigated whether db-cAMP has a synergistic effect when co-administering Daoy cells with GCV. Results showed that there was no significant difference in cell survival between cells with or without db-cAMP treatment for 24 or $72 \mathrm{~h}$ after GCV administration $(\mathrm{P}>0.05)$ (Fig. 7), which excluded the influence of db-cAMP on GCV cytotoxicity.

Effect of db-cAMP on Bcl-2 expression and drug cytotoxicity. The expression of Bcl-2 protein was detected by western blot analysis, and results showed that db-cAMP treatment downregulated the Bcl-2 level in a concentration-dependent manner in Daoy cells (Fig. 8). 


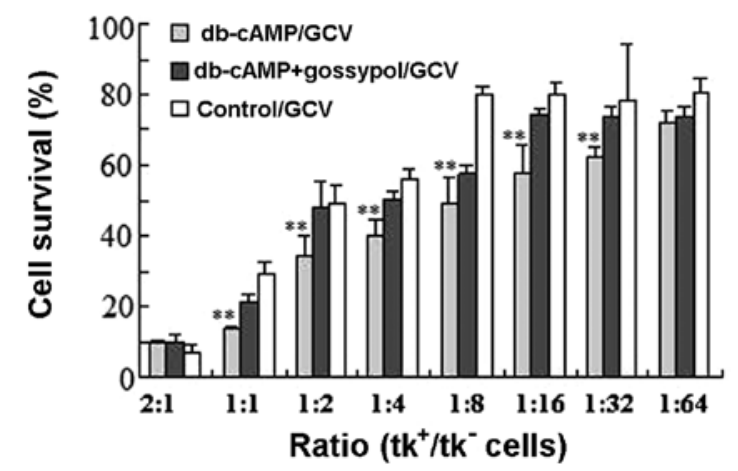

Figure 6. MTT assay in the presence and absence of db-cAMP. Daoy cells were treated with or without db-cAMP. Five thousand Daoy cells were mixed in complete culture medium with Daoy-tk ${ }^{+}$cells at the ratio of 1:2-64:1. These cell populations were then treated with $100 \mu \mathrm{mol} / 1 \mathrm{GCV}$ for $72 \mathrm{~h}$, and an MTT assay was performed to measure their cell viability. The results represent the mean \pm SD of triplicates ( $(\mathrm{P}<0.05)$.

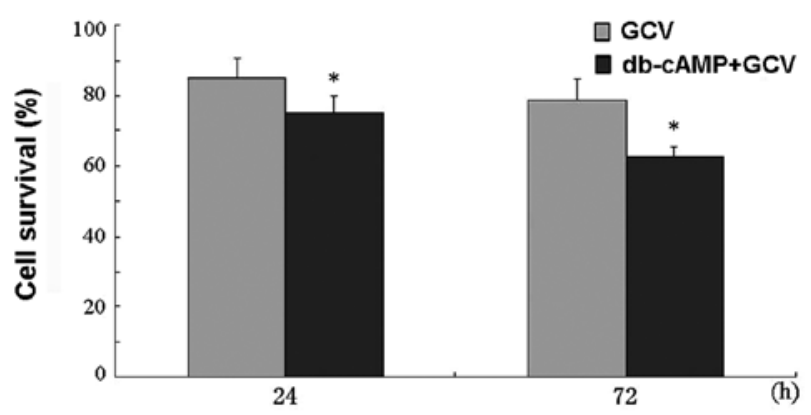

Figure 7. Effect of db-cAMP on GCV cytotoxicity by MTT assay. Daoy cells were treated with $100 \mu \mathrm{mol} / \mathrm{l} \mathrm{GCV}$ combined with or without db-cAMP and were seeded at equal cell densities and cultured for 24 or $72 \mathrm{~h}$. MTT assays were performed to estimate cell survival $(\mathrm{P}>0.05)$. Each bar represents the mean \pm SD of triplicates.

Meanwhile, the results of flow cytometry (Fig. 9) showed db-cAMP greatly increased the early apoptosis rate of Daoy cells, and when cells were treated with db-cAMP combined with gossypol, the early apoptosis rate was only slightly augmented compared with the control. These data indicated that db-cAMP may induce early apoptosis in Daoy cells, which was blocked by gossypol.

Cytotoxicity of each chemotherapeutic drug in Daoy cells was measured by determing the $\mathrm{IC}_{50}$ value (Fig. 10). The $\mathrm{IC}_{50}$ values of temozolomide (TMZ) and teniposide (VM26) were significantly decreased in cells treated with db-cAMP, indicating the cytotoxicity of both agents was greatly enhanced by $\mathrm{db}$-cAMP (reaching $>5$-fold of the control, $\mathrm{P}<0.05$ ). Importantly, a Bcl-2 antagonist, ABT-737, also augmented their chemosensitivity (reaching $\sim 2.5$-fold over control, $\mathrm{P}<0.05$ ), indicating that a decrease in Bcl-2 may increase the sensitivity of the two agents, and the upregulated chemosensitivity by db-cAMP may partly result from the repression of Bcl-2 expression.

\section{Discussion}

In the present study, we first demonstrated the direct influence of db-cAMP on BE and chemosensitivity in human medullo-

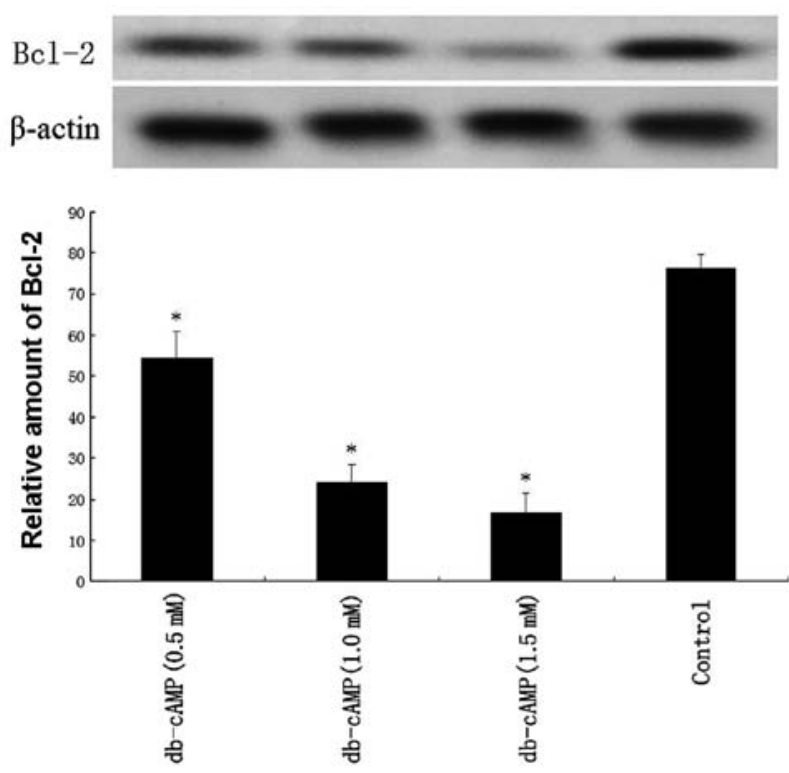

Figure 8. Effect of db-cAMP on Bcl-2 protein expression by western blot analysis. The expression of $\mathrm{Bcl}-2$ protein was reduced by $\mathrm{db}-\mathrm{cAMP}$ in a concentration-dependent manner in Daoy cells $\left({ }^{*} \mathrm{P}<0.05\right.$, compared with the control group).

blastoma. A Cx43 inhibitor, gossypol, blocked the effect of $\mathrm{db}$-cAMP by downregulating the $\mathrm{Cx} 43$ expression and thus GJIC function, suggesting a role of $\mathrm{Cx} 43$ in db-cAMPinduced increase of BE. Meanwhile, db-cAMP decreased the Bcl-2 expression and increased apoptosis, which may be a possible mechanism of db-cAMP-augmented chemosensitivity in medulloblastoma.

Previous studies demonstrated that the upregulation of $\mathrm{Cx} 43$, one of the major GJIC components, leads to an increased BE in suicide gene therapy and the sensitivity of several chemotherapeutic agents $(16,21,22)$. Expression of Cx43 was found to be reduced in many human carcinomas, including glioblastoma (7). In this study we found comparatively low levels of Cx 43 protein in $3 \mathrm{MB}$ cell lines (D283Med, Daoy and D341Med), indicating a role in the development or progression of MB. Chemical induction of $\mathrm{Cx} 43$ has been more effective compared with gene delivery, since a larger cancer cell population is obtained. Therefore, we aimed to identify potential chemicals to enhance $\mathrm{BE}$ in a $\mathrm{Cx} 43$ mediated manner in MB. A number of classes of chemicals were found to increase $\mathrm{Cx} 43$, including retinoids, cAMP, and carotenoids (23). Numerous studies have demonstrated that cAMP is a potent inducer of differentiation, which may also decrease proliferation of neoplastic cells (24). Therefore, we selected db-cAMP as the potent chemical to treat Daoy cells. We used Daoy cells in the present study since Daoy cells grow in adhesion and are more suitable for in vitro experiments. Meanwhile, Cx43 expressed low levels in all 3 cell lines, which is a common phenomenon in tumor cells, and db-cAMP increased the Cx43 expression in D283Med and D341Med cells (data not shown). Therefore, to the best of our knowledge, these cells may similarly express the $\mathrm{Cx} 43$ gene and we selected Daoy cells due to their growth characteristic advantages. 

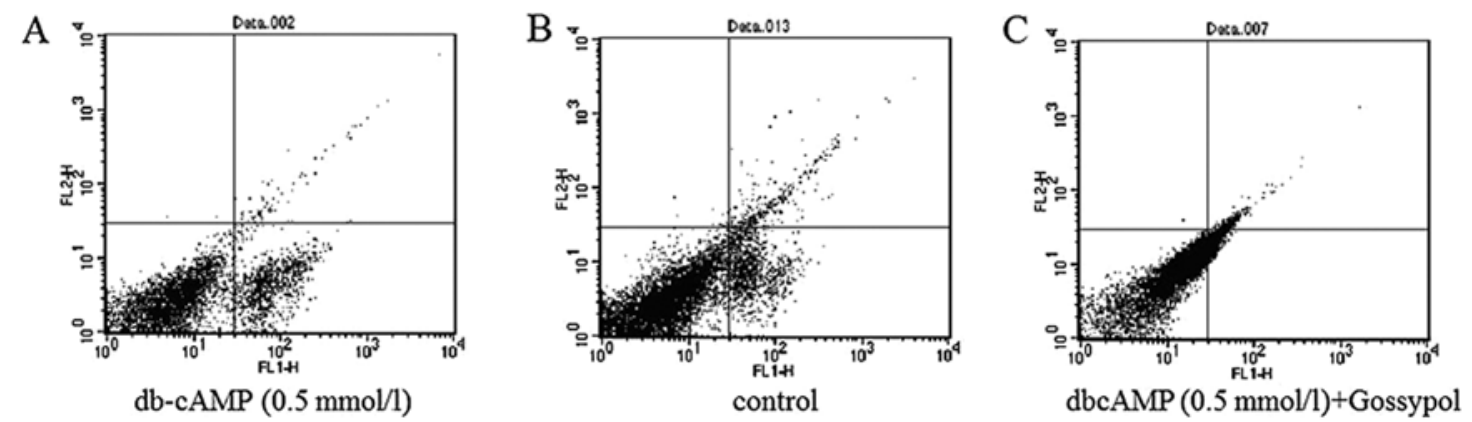

Figure 9. Daoy cells were treated with db-cAMP (or combined with gossypol). Apoptosis was detected using flow cytometric analysis. db-cAMP greatly increased the early apoptosis rate of Daoy cells, and when cells were treated with db-cAMP combined with gossypol, the early apoptosis rate was only slightly augmented compared with the control.
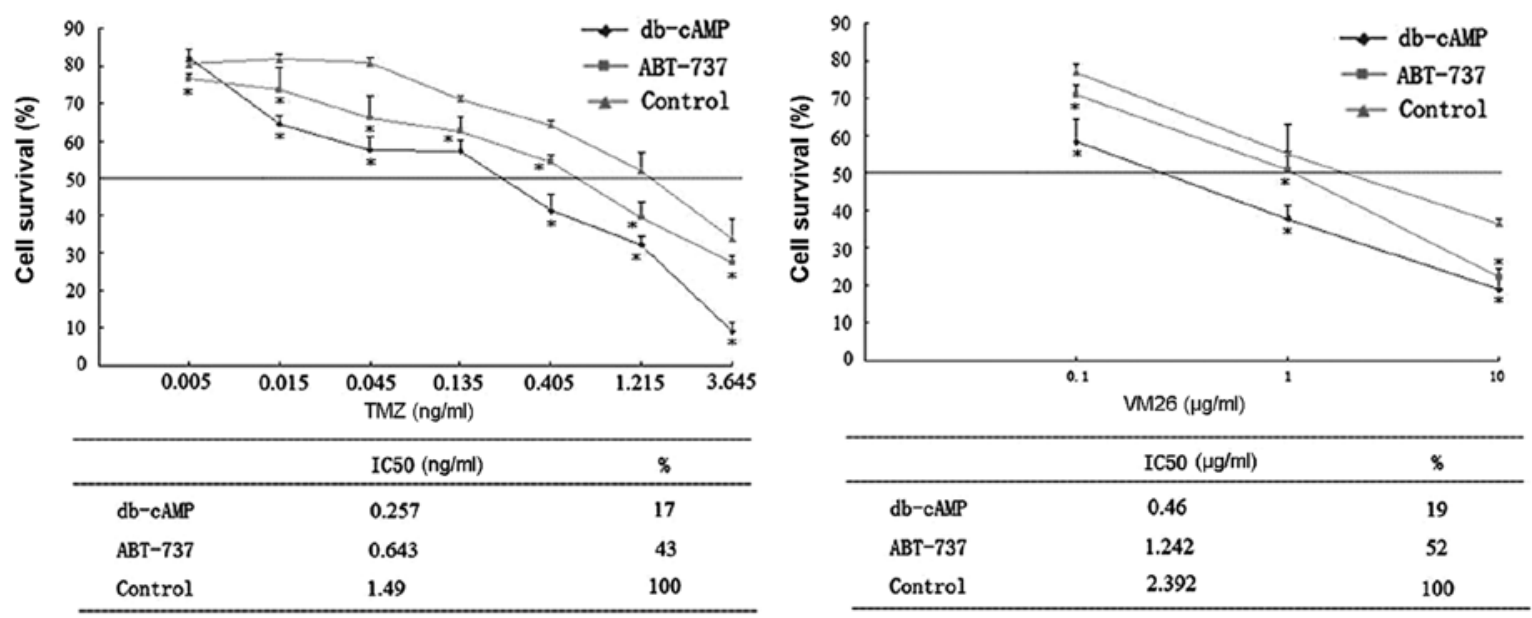

Figure 10. Effect of db-cAMP on drug cytotoxicity. db-cAMP or ABT-737-treated or untreated Daoy cells were re-suspended and incubated for $18 \mathrm{~h}$, cells were treated with various concentrations of temozolomide (TMZ) or teniposide (VM26) and incubated for another $96 \mathrm{~h}$. The number of viable cells was determined by an MTT assay. The results represent the mean $\pm \mathrm{SD}$ of triplicates ( $\mathrm{P}<0.05$, compared with the control group).

Our results demonstrated that db-cAMP increased the expression of the $\mathrm{Cx} 43$ protein as well as its phosphorylated forms in Daoy cells, in a dose-dependent manner. The GJIC function was also greatly enhanced by db-cAMP. However, the effect was blocked by the $\mathrm{Cx} 43$ inhibitor, gossypol. Cx43 protein is phosphorylated by various protein kinases $(25,26)$, including PKC and MAP kinases. Previous studies have shown that activation of cAMP-dependent protein kinase leads to a rapid augmentation in $\mathrm{Cx} 43$ phosphorylation (27), and increases intercellular communication $(28,29)$. Our results correspond with these reports, which demonstrated the treatment of db-cAMP in Daoy cells leads to an evident increase in phosphorylated $\mathrm{Cx} 43$ and thus GJIC function. Meanwhile, we noted that in cells treated with both db-cAMP and gossypol, the $\mathrm{Cx} 43$ protein level was even lower than that of the control, but the GJIC function in these cells was almost the same as the control. A possible explanation is that gossypol may inhibit the expression of both the basal and db-cAMP-induced Cx43 expression in Daoy cells, but the GJIC function may also be influenced by an other effect of db-cAMP apart from the upregulation of $\mathrm{Cx} 43$, which cannot be completely blocked by gossypol.
There are a number of suicide gene systems for treating different tumors, among which the HSV-tk/GCV is used the most widely. Interestingly, studies show that the enhancement of BE may further increase the therapeutic effect of HSV-tk as a more toxic effect can spread from the transduced cells to the neighboring untransduced cells. Several hypotheses have been proposed for its mechanism, including the involvement of the immune response $(30,31)$, apoptosis (32), endocytosis of toxic cell debris (33) or blood vessel destruction (34). In the present study, we first transfected Daoy cells with retroviral vectors containing the $H S V-t k$ gene, and an indirect immunofluorescence assay and RT-PCR showed that HSV-tk was stably expressed. To investigate the effects of db-cAMP on BE, an MTT assay was performed, which showed that BE was enhanced by db-cAMP in Daoy cells. Cell killing was significantly increased when the ratio of $\mathrm{tk}^{+} / \mathrm{tk}$ cells was 1:1-1:16, which suggest that db-cAMP increased cell killing significantly when Daoy-tk ${ }^{+}$cells were in a small proportion, which is a common situation found in suicide gene therapy. In this study cell killing was no longer increased when the ratio of $\mathrm{tk}^{+} / \mathrm{tk}$ cells was $2: 1$. The reason may be that when the GJIC function (the most important factor affecting BE) reached a 
maximum, BE was no longer enhanced, even when gap junction assembly was further enhanced. When the $\mathrm{Cx} 43$ inhibitor, gossypol, which downregulates Cx43 and decreases GJIC specifically, was added subsequently, cell killing decreased significantly, regardless of the proportion of $\mathrm{tk}^{+}$cells. These results suggest that by regulating the $\mathrm{Cx} 43$ expression and GJIC function, db-cAMP may greatly enhance the BE in Daoy cells.

Furthermore, we investigated the role of db-cAMP in the cytotoxicity of chemotherapeutic agents temozolomide (TMZ) and teniposide (VM26). Essentially the mechanism used to kill cancer cells by inducing apoptosis with cytotoxic anticancer drugs is commonly used in the treatment of MB. Thus, we examined the expression of $\mathrm{Bcl}-2$, an apoptosis blocker, and revealed db-cAMP downregulated the levels of $\mathrm{Bcl}-2$ protein in a concentration-dependent manner. db-cAMP induced early apoptosis in Daoy cells, which was blocked by gossypol. Our results showed that db-cAMP induced the cytoxicity of the two agents, which partly resulted from its downregulation of Bcl-2 expression and induction of apoptosis. We presume that the downregulation of Bcl-2 by db-cAMP could re-start the apoptosis pathway it blocked, activate the apoptosis-related gene and increase apoptosis of tumor cells. Another important factor is our selection of temozolomide and teniposide, whose molecular weight was $<1 \mathrm{kDa}$. These agents can pass through gap junctions more easily, avoiding the influence of drug particle size on the experimental results.

It is also possible that the db-cAMP effect on BE was also a result of its repressing Bcl-2 expression by the activation of apotosis. At the same time, db-cAMP augmented the cytotoxicity of TMZ and VM26 (>5-fold of the control) more significantly than the effect of the Bcl-2 antagonist ( 2.5-fold over control), indicating that the increase in chemosensitivity by db-cAMP may also result from other factors besides the suppression of Bcl-2, such as the augmentation of Cx43 expression and the GJIC function, which could spread the effect of the chemical agents more widely.

In summary, our study demonstrates the beneficial effect of $\mathrm{db}$-cAMP in the treatment of human medulloblastoma through its upregulation of $\mathrm{BE}$ and increased chemosensitivity through Cx43 and Bcl-2-mediated pathways. The data revealed that $\mathrm{db}$-cAMP increased the $\mathrm{Cx}-43$ expression and GJIC function in Daoy cells. As a result, it enhanced the BE in the HSV-tk/GCV system. Meanwhile, db-cAMP repressed the Bcl-2 expression and induced apoptosis, which may be a possible way to increase the sensitivity of temozolomide and teniposide. The present study provides certain molecular mechanisms for clinical trials in the gene therapy of medulloblastoma.

\section{Acknowledgements}

This study was supported by the Natural Science Foundation of China (nos. 30800451, 30872656, 30700861, 30670723, 30973079 and 30772246).

\section{References}

1. Taylor RE, Bailey CC, Robinson K, et al: Results of a randomized study of preradiation chemotherapy versus radiotherapy alone for non-metastatic medulloblastoma: the International Society of Paediatric Oncology/United Kingdom Children's Cancer Study Group PNET-3 Study. J Clin Oncol 21: 1581-1591, 2003.
2. Zeltzer PM, Boyett JM, Finlay JL, et al: Metastasis stage, adjuvant treatment, and residual tumor are prognostic factors for medulloblastoma in children: conclusions from the Children's Cancer Group 921 Randomized Phase III Study. J Clin Oncol 17: 832-845, 1999.

3. Kozarsky KF and Wilson JM: Gene therapy: adenovirus vectors. Curr Opin Genet Dev 3: 499-503, 1993.

4. Pützer BM, Bramson JL, Addison CL, et al: Combination therapy with interleukin-2 and wild-type p53 expressed by adenoviral vectors potentiates tumor regression in a murine model of breast cancer. Hum Gene Ther 9: 707-718, 1998.

5. Nishi M, Kumar NM and Gilula NB: Developmental regulation of gap junction gene expression during mouse embryonic development. Dev Biol 146: 117-130, 1991.

6. Houghton FD: Role of gap junctions during early embryo development. Reproduction 129: 129-135, 2005.

7. Vinken M, Vanhaecke T, Papeleu P, et al: Connexins and their channels in cell growth and cell death. Cell Signal 18: 592-600, 2006.

8. Trosko JE and Chang CC: Modulation of cell-cell communication in the cause and chemoprevention/chemotherapy of cancer. Biofactors 12: 259-263, 2000.

9. Mesnil M, Piccoli C, Tiraby G, et al: Bystander killing of cancer cells by herpes virus thymidine kinase gene is mediated by connexins. Proc Natl Acad Sci USA 93: 1831-1835, 1996.

10. Elshami AA, Saavedra A, Zhang H, et al: Gap junctions play a role in the 'bystander effect' of the herpes simplex thymidine kinase/ganciclovir system in vitro. Gene Ther 3: 85-92, 1996.

11. Alexander DB and Goldberg GS: Transfer of biologically important molecules between cells through gap junction channels. Curr Med Chem 10: 2045-2058, 2003.

12. Yamasaki H: Gap junction intercellular communication carcinogenesis. Carcinogenesis 11: 1051-1058, 1990.

13. Yamasaki H, Mesnil M, Omori Y, et al: Intercellular communication and carcinogenesis. Mutat Res 333: 181-188, 1995.

14. Zhou DR, Zhou YC, Cui GH, et al: Gossypol repressed the gap junctional intercellular communication between Sertoli cells by decreasing the expression of Connexin43. Toxicol In Vitro 22: 1719-1725, 2008.

15. Rosolen A, Frascella E, di Francesco C, Todesco A, et al: In vitro and in vivo antitumor effect of retrovirus mediated herpes simplex thymidine kinase gene transfer in human medulloblastoma. Gene Ther 5: 113-120, 1998

16. Huang RP, Hossain MZ, Huang R, et al: Connexin 43 (cx43) enhances chemotherapy-induced apoptosis in human glioblastoma cells. Int J Cancer 92: 130-138, 2001.

17. $\mathrm{Pu} \mathrm{K}, \mathrm{Li} \mathrm{SY}$, Gao Y, et al: Bystander effect in suicide gene therapy using immortalized neural stem cells transduced with herpes simplex virus thymidine kinase gene on medulloblastoma regression. Brain Res 1369: 245-252, 2011.

18. Miyashita T and Reed JC: Bcl-2 oncoprotein blocks chemotherapy-induced apoptosis in a human leukemia cell line. Blood 81: 151-157, 1993.

19. Piche A, Grim J, Rancourt C, et al: Modulation of Bcl-2 protein levels by an intracellular anti-Bcl-2 single-chain antibody increases drug-induced cytotoxicity in the breast cancer cell line MCF-7. Cancer Res 58: 2134-2140, 1998.

20. Reed JC, Miyashita T, Takayama S, et al: BCL-2 family proteins: regulators of cell death involved in the pathogenesis of cancer and resistance to therapy. J Cell Biochem 60: 23-32, 1996.

21. Jimenez T, Fox WP, Naus CC, et al: Connexin over-expression differentially suppresses glioma growth and contributes to the bystander effect following HSV-thymidine kinase gene therapy. Cell Commun Adhes 13: 79-92, 2006.

22. Zhang A, Wang Qy, Han Z, et al: Relationship between the expression of connexin 43 and bystander effect of suicide gene therapy in ovarian cancer. J Huazhong Univ Sci Technolog Med Sci 24: 476-479, 2004.

23. Carystinos GD, Alaoui-Jamali MA, Phipps J, et al: Upregulation of gap junctional intercellular communication and connexin 43 expression by cyclic-AMP and all-trans-retinoic acid is associated with glutathione depletion and chemosensitivity in neuroblastoma cells. Cancer Chemother Pharmacol 47: 126-132, 2001.

24. Chen TC, Hinton DR, Zidovetzki R and Hofman FM: Upregulation of the cAMP/PKA pathway inhibits proliferation, induces differentiation, and leads to apoptosis in malignant gliomas. Lab Invest 78: 165-174, 1998.

25. Goodenough DA, Goliger JA and Paul DL: Connexins, connexons, and intercellular communication. Annu Rev Biochem 65: 475-502, 1996. 
26. Laird DW, Puranam KL and Revel JP: Turnover and phosphorylation dynamics of connexin43 gap junction protein in cultured cardiac myocytes. Biochem J 273: 67-72, 1991.

27. Granot I and Dekel N: Phosphorylation and expression of connexin-43 ovarian gap junction protein are regulated by luteinizing hormone. J Biol Chem 269: 30502-30509, 1994.

28. Burt JM and Spray DC: Ionotropic agents modulate gap junctional conductance between cardiac myocytes. Am J Physiol 254 H1206-H1210, 1988.

29. Godwin AJ, Green LM, Walsh MP, et al: In situ regulation of cell-cell communication by the cAMP-dependent protein kinase and protein kinase C. Mol Cell Biochem 127-128: 293-307, 1993.

30. Vile RG, Nelson JA, Castleden S, et al: Systemic gene therapy of murine melanoma using tissue specific expression of the HSVtk gene involves an immune component. Cancer Res 54: 6228-6234, 1994.
31. Caruso M, Panis Y, Gagandeep S, et al: Regression of established macroscopic liver metastases after in situ transduction of a suicide gene. Proc Natl Acad Sci USA 90: 7024-7028, 1993.

32. Samejima Y and Meruelo D: 'Bystander killing' induces apoptosis and is inhibited by forskolin. Gene Ther 2: 50-58, 1995 .

33. Freeman SM, Abboud CN, Whartenby KA, et al: The 'bystander effect': tumor regression when a fraction of the tumor mass is genetically modified. Cancer Res 53: 5274-5283, 1993.

34. Ram Z, Walbridge S, Shawker T, et al: The effect of thymidine kinase transduction and ganciclovir therapy on tumor vasculature growth of 9L gliomas in rats. J Neurosurg 81: 256-260, 1994. 